\title{
O ensino remoto emergencial no contexto de pandemia da Covid-19: Relatos de uma experiência desafiadora e exitosa numa turma de Licenciatura em Química do IFRN
}

\author{
Emergency remote teaching in the Covid-19 Pandemic Context: Reports of a challenging and \\ successful experience in an Undergraduate Chemistry class at IFRN \\ Enseñanza remota de emergencia en el contexto de la pandemia de Covid-19: Informes de una \\ experiencia desafiante y exitosa en una clase de Química de Pregrado en IFRN
}

Received: 04/05/2021 | Reviewed: 04/12/2021 | Accept: 04/13/2021 | Published: 04/25/2021

\author{
Argeu Cavalcante Fernandes \\ ORCID: https://orcid.org/0000-0002-0222-9883 \\ Instituto Federal do Rio Grande do Norte, Brasil \\ E-mail: argeu.fernandes@ifrn.edu.br
}

\begin{abstract}
Resumo
Este artigo tem por objetivo descrever e relatar a experiência vivida no Ensino Remoto Emergencial (ERE), durante o módulo I de um total de seis módulos, na perspectiva do olhar dos discentes levando-os a refletir sobre a formação docente e os desafios para a educação no século XXI. A presente pesquisa tem natureza qualitativa, evidenciando a qualidade social, e do tipo descritiva, que no âmbito educacional, privilegia o processo em detrimento do produto final. Se realizou com 17 estudantes do $1^{\circ}$ semestre do curso de licenciatura em Química do IFRN localizado no interior do estado potiguar, sendo o ambiente virtual de aprendizagem utilizado o Google Classroom. Apesar das limitações, os alunos pesquisados revelaram experiências mais exitosas e superaram as expectativas quanto ao novo formato de ensino e demonstraram boa aceitação, o que nos leva a refletirmos sobre a perspectiva de desenvolvermos atividades de ensino no ambiente virtual de aprendizagem mesmo durante o ensino presencial, no formato que denominamos de ensino híbrido, que integra parte das atividades desenvolvidas ao formato remoto. Essa experiência mostra que um laboratório para estudar e aplicar ferramentas digitais aliadas ao ensino numa abordagem investigativa é viável e abre leques de novas possibilidades com vistas a melhorar a formação docente e, por consequência, o ensino a médio e longo prazo.
\end{abstract}

Palavras-chave: Ensino remoto emergencial; Formação docente; Ensino de química; Covid-19.

\begin{abstract}
This article aims to describe and report the experience lived in emergency remote education (ERE), during module I of a total of six modules, from the perspective of the students' perspective, leading them to reflect on teacher training and challenges for education in the 21 st century. The present research has a qualitative nature, showing the social quality, and the descriptive type, which in the educational scope, privileges the process to the detriment of the final product. It took place with 17 students from the 1st semester of the degree course in Chemistry at IFRN located in the interior of the state of Rio Grande do Sul, and the virtual learning environment used is Google Classroom. Despite the limitations, the students surveyed revealed more successful experiences and exceeded expectations regarding the new teaching format and demonstrated good acceptance, which leads us to reflect on the perspective of developing teaching activities in the virtual learning environment even during classroom teaching., in the format that they call hybrid education, which integrates part of the activities developed to the remote format. This experience shows that a laboratory to study and apply digital tools combined with teaching in an investigative approach is feasible and opens up new possibilities with a view to improving teacher training and, consequently, teaching in the medium and long term.
\end{abstract}

Keywords: Emergency remote education; Teacher education; Chemistry teaching; Covid-19.

\section{Resumen}

Este artículo tiene como objetivo describir y reportar la experiencia vivida en educación remota de emergencia (ERE), durante el módulo I de un total de seis módulos, desde la perspectiva de los estudiantes, llevándolos a reflexionar sobre la formación docente y los desafíos para la educación. en el siglo 21. La presente investigación tiene un carácter cualitativo, mostrando la calidad social, y el tipo descriptivo, que en el ámbito educativo privilegia el proceso en detrimento del producto final. Se llevó a cabo con 17 estudiantes del 1er semestre de la carrera de Química de la IFRN ubicada en el interior del estado de Rio Grande do Sul, con el entorno virtual de aprendizaje utilizado por Google 
Classroom. A pesar de las limitaciones, los estudiantes encuestados revelaron experiencias más exitosas y superaron las expectativas con respecto al nuevo formato de enseñanza y demostraron buena aceptación, lo que nos lleva a reflexionar sobre la perspectiva de desarrollar actividades docentes en el entorno de aprendizaje virtual incluso durante la docencia en el aula, En el formato que ellos denominan educación híbrida, que integra parte de las actividades desarrolladas al formato remoto. Esta experiencia demuestra que un laboratorio para estudiar y aplicar herramientas digitales combinado con la docencia en un enfoque investigativo es factible y abre nuevas posibilidades con miras a mejorar la formación del profesorado y, en consecuencia, la docencia a medio y largo plazo.

Palabras clave: Educación remota de emergencia; Educación del professorado; Enseñanza de la química; Covid-19.

\section{Introdução}

Em virtude da pandemia da Covid-19, escolas e instituições de ensino do mundo inteiro se viram obrigadas a encerrar as atividades presenciais como precaução para evitar a propagação do vírus SARS-Cov-2, um novo tipo de coronavírus mais resistente que os anteriores causador da doença Covid-19, responsável por comprometer as vias aéreas respiratórias dos pacientes acometidos. (Banerjee, Perera \& Tillekeratne, 2021).

De uma forma repentina, as escolas do país inteiro tiveram que fechar as portas, uma vez que esse espaço é um ambiente onde a interação entre os alunos e toda comunidade escolar é bastante intensa, sendo motivo de aflição e angústia para milhões de brasileiros por vários motivos, dentre eles: aumento da ansiedade nos alunos por estarem em isolamento social e longe do convívio como os colegas; incerteza com relação à preparação para o Exame Nacional do Ensino Médio (ENEM); atraso para conclusão de curso a nível médio, técnico, de graduação e pós-graduação; expectativa para aulas online; preocupação dos professores sem capacitação para um novo formato de ensino; alunos com dificuldade de acesso à internet e sem dispositivos eletrônicos para assistirem as aulas remotas etc. Enfim, são várias as situações complexas que podemos levantar sobre um novo formato de ensino em uma pandemia.

O Ensino Remoto Emergencial (ERE) no âmbito do IFRN foi proposto ao longo de uma extensa e profunda discussão a respeito da oferta de ensino com qualidade e que abrangesse toda a comunidade escolar pensando, sobretudo, nos alunos de baixa renda que têm dificuldade de acesso à internet e/ou não possuem aparelhos eletrônicos como smartphones, tablets e notebooks que deem suporte às aulas remotas, e nos alunos com necessidades educacionais específicas.

As aulas e as atividades acadêmico-administrativas presenciais no IFRN foram suspensas no primeiro bimestre de 2020 seguindo as orientações da Resolução no 22/2020 (Brasil, 2020). Um plano de retomada das atividades acadêmicas foi proposto com princípios norteadores, diretrizes e planejamento pedagógicos voltados para o ERE composto por momentos síncronos e assíncronos compondo a carga-horária das disciplinas e componentes curriculares. Foi ofertado um curso de capacitação sobre ensino remoto emergencial para os docentes abrangendo todos os 21 campi distribuídos por todas as regiões do estado potiguar. Assim, o calendário foi retomado por módulos com momentos formativos e de ambientação para os estudantes conhecerem os ambientes virtuais de aprendizagem bem como se dará o ensino nesse novo formato.

Este artigo tem por objetivo descrever e relatar a experiência vivida no ERE, durante o módulo I de um total de seis módulos, na perspectiva do olhar dos discentes levando-os a refletir sobre a formação docente e os desafios para a educação no século XXI. A disciplina ministrada pelo docente foi Química Geral I numa turma de licenciatura do primeiro semestre do IFRN campus Currais Novos. Os desafios enfrentados pelos docentes, estudantes, direção acadêmica, coordenação pedagógica e técnicos administrativos tornam-se relevantes para ampliar as discussões sobre o ensino de química, de forma geral, e a formação de futuros professores de química que experienciaram um novo formato de ensino que muitos docentes não viveram durante sua formação acadêmica. 


\subsection{A rede federal de ensino e a formação de professores na área de ciências}

Uma das características mais destacadas em pesquisas sobre formação docente é a baixa oferta e procura de cursos superiores nas áreas de biologia, física, matemática e química em virtude de diversos fatores, tais como poucos recursos para implantação de cursos de graduação em regiões mais distantes dos grandes centros urbanos; as dificuldades de assimilação dos conteúdos /disciplinas da área de exatas acabam não compensando os baixos salários da carreira do magistério (muitos optam em cursar engenharias por terem salários maiores que a profissão de professores); o desestímulo quanto às dificuldades encontradas na sala de aula leva a muitos não procurarem os cursos de formação docente; entre outros fatores (Lôbo, 2008; Maldaner \& Santos, 2010; Carvalho \& Gil-pérez, 2011; Libâneo, 2011; Maués, Segenreich \& Otranto, 2015; Cardoso \& Castro, 2020).

Não obstante, percebemos a importância de políticas públicas, sobretudo a partir de 2008, que viabilizaram a expansão da rede federal de ensino com oferta de cursos de nível médio e técnico nos diversos eixos tecnológicos dos catálogos nacionais, com enfoque especial, aos cursos de formação inicial docente na área das ciências exatas (Turmena \& Azevedo, 2017). Para Maués, Segenreich e Otranto (2015, p.46), o destaque dado à formação de docentes, na área das ciências exatas, ocorreu a partir dos anos 1990 devido à defasagem escolar e os índices de aprovação/reprovação, momento em que os governos passaram a ter "preocupação com a formação, na medida em que imputavam ao professor a responsabilidade pelo processo de ensino e aprendizagem. [...] se instalou uma política de responsabilização dos professores pelos resultados que os alunos obtêm nos exames externos e padronizados".

No contexto de políticas públicas para expansão da oferta de formação docente, são criados, em 2008, pela lei n ${ }^{\circ}$ 11.892 de 29 de dezembro, os 38 Institutos Federais (IFs) no âmbito da Rede Federal de Educação Profissional, Científica e Tecnológica do país, composta pela Universidade Tecnológica Federal do Paraná - UFTFPR; os 2 Centros Federais de Educação tecnológica, no Rio de janeiro (CEFET-RJ), e em Minas Gerais, (CEFET-MG); as 24 Escolas Técnicas Vinculadas às Universidades Federais; o Colégio Pedro II, também no Rio de Janeiro (Brasil, 2012); além dos IFs. (Brasil, 2008).

Contempladas as finalidades e características, um dos objetivos dos IFs, conforme o artigo $7^{\circ}$ e parágrafo sexto, alínea b, é ofertar no campo da educação superior "cursos de licenciatura, bem como programas especiais de formação pedagógica, com vistas na formação de professores para a educação básica, sobretudo nas áreas de ciências e matemática, e para a educação profissional” (Brasil, 2008).

Dessa maneira, Lima (2013) ressalta que a contribuição dos IFs na formação docente concentra-se na oferta de cursos de licenciaturas voltadas para educação básica (especialmente biologia, física, matemática e química) no período da noite, sobretudo na região nordeste do país e afastada das capitais. Dentro do prisma político, a região nordeste é a que apresenta os mais baixos índices de escolarização que são reflexos diretos da falta de investimento em formação docente tendo, portanto, chamado mais atenção aos olhos do governo.

Entretanto, essa atenção não se deu de hora para outra, mas sim após anos de lutas, embates políticos e anseios da população que viu em meados do século XX o aumento da oferta de vagas na educação básica, em virtude do crescimento populacional. Com isso, naturalmente surgiu a pungente necessidade de professores, que por muitos anos teve que ser suprimida por professionais sem formação ou por profissionais que tenham cursado cursos de formação com carga horária reduzida, ficando as ciências exatas muitas vezes esquecidas ou negligenciadas (Gatti; Barretto, 2009).

Com a expansão da rede federal de educação, sobretudo com a criação dos IFs com autonomias de autarquias governamentais, o orçamento para investir na formação de professores na área de ciências possibilitou a contratação de profissionais qualificados, infraestrutura adequada de laboratórios com suporte de profissionais técnicos para auxiliar no desenvolvimento de pesquisa, ensino e extensão; plano de carreira para o magistério com incentivo à qualificação e reconhecimento profissional. Apesar de não ter tradição, os IFs têm demonstrado ser uma solução satisfatória para o problema 
da falta de oferta de cursos de formação docente, especialmente nas regiões interiores mais pobres do país (Lima, 2013; Maués, Segenreich \& Otranto, 2015; Turmena \& Azevedo, 2017; Oliveira, Sales, \& Silva, 2017; Pena et al, 2019).

\subsection{Educação emancipatória e o ensino investigativo}

A formação do sujeito crítico e reflexivo capaz de se posicionar diante de variados temas que impactam a sociedade moderna, tais como política, tecnologia, educação e meio ambiente, parte do ensino contextualizado com fundamentação científica e prática educativa onde o próprio sujeito é colocado como personagem principal na construção do seu conhecimento. Definitivamente, essa visão impõe ao professor, um olhar autorreflexivo sobre sua própria formação e sua prática educativa, ou seja, não cabe mais, na educação do século atual e numa sociedade moderna e tecnológica, a concepção do ensino tradicional (Maldaner \& Santos, 2010; Libâneo, 2011; Carvalho \& Gil-pérez, 2011; Chassot, 2015).

Para Guimarães, Echeverría e Moraes (2006), a mudança e quebra de paradigmas nos modelos didáticos parte da necessidade de colocar o professor como centro desse processo de mudança e vê-lo como sujeito fundamental em qualquer reforma educacional que se pensar necessária. Enquanto essa quebra de paradigma ocorre, o ensino tradicional dá espaço ao ensino investigativo que propõe personificar, tanto aluno quanto professor, como sujeitos ativos no processo de ensino e aprendizagem. Nesse modelo (Figura 1), é enfatizado a problematização através do uso de situações problemas que pressupõe do aluno a postura investigativa e consequente formulação das hipóteses e proposição de soluções. (García \& Porlán, 2000).

Figura 1. Sequência do modelo de ensino investigativo.

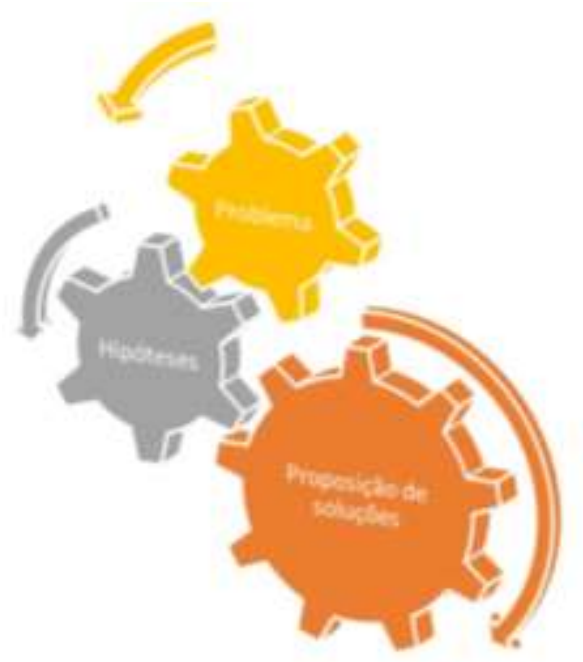

Fonte: Autores (2021).

No ensino de ciências, se almeja justamente essa tomada de consciência na construção do conhecimento e repensarmos a prática docente/formação docente nesse sentido, tem sido alvo de muitos questionamentos e o sentido para muitos pesquisadores brasileiros continuarem sonhando com uma educação de qualidade e emancipadora. Tomando como bases vários estudos na área de ciências (Zompero \& Laburu, 2011; Trópia, 2011; Sasseron, 2015; Belluco \& Carvalho, 2014; Sartori \& Andrade, 2018; Cardoso e Castro, 2020) o ensino problematizador promove rupturas ao passo que ocorre a seguinte sequência, como mostrado na Figura 2 a seguir: 
Figura 2. ruptura de modelos didáticos numa perspectiva emancipadora.

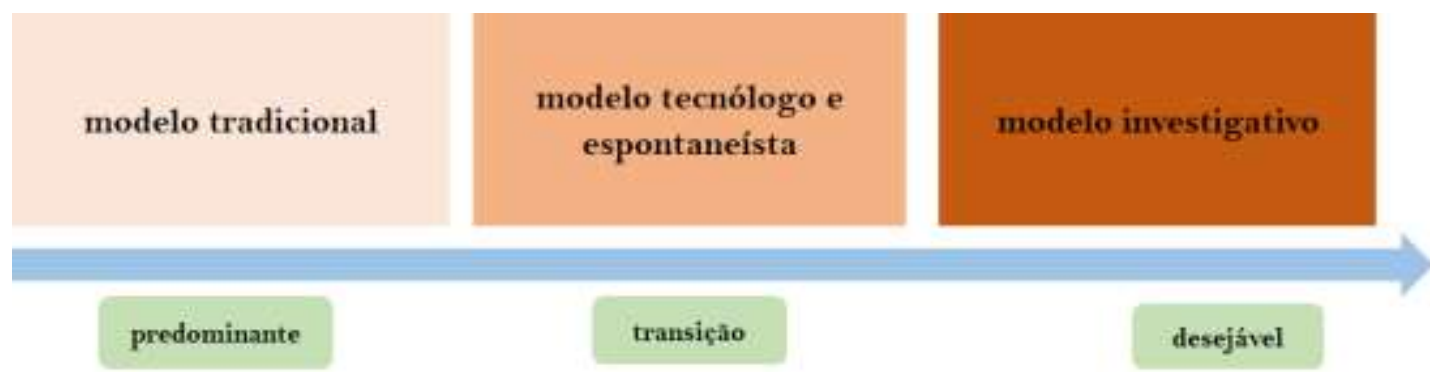

Fonte: Autores (2021).

Nessa perspectiva, Carvalho (2015) ressalta como produto da investigação, a resolução de determinado problema com auxílio de um adulto (personificado aqui pela figura do professor) ou por pares (pela colaboração de colegas e companheiros) resultando no processo que favorece o desenvolvimento potencial. Para a autora, o nível de desenvolvimento potencial "é o conjunto de conhecimentos e habilidades que a pessoa potencialmente pode aprender, mas ainda não completou o processo, porém tem grande probabilidade para atingir com a orientação de outro, podendo esse outro ser um adulto (professor) ou um colega de classe" (Carvalho, 2015, p.05). Percebe-se que o ensino nesse novo formato pressupõe necessariamente a interação social.

Nesse caminho, a construção do conhecimento sugere a que o processo de aprendizagem é a busca de resposta a uma determinada questão, e nessa busca, na maioria das vezes, o erro é inevitável. Entretanto, para Bachelard, mesmo uma proposta de solução imbuída de erros é vista de forma positiva, pois ele relata que: "acho surpreendente que os professores de ciências, mais do que os outros se possível, não compreendam que alguém não compreenda. Poucos são os que se detiveram na psicologia do erro, da ignorância e da irreflexão" (Bachelard, 1996, p. 23). Consequentemente, é papel do professor/mediador aprender trabalhar em cima do erro do seu aluno propondo mecanismo para assimilação e reconciliação dos conhecimentos subsunçores ao conhecimento novo produzido (Ribeiro \& Nuñez, 2004).

\subsection{Ambientes virtuais de aprendizagem e ferramentas tecnológicas no trabalho docente}

Com o isolamento social imposto pela pandemia de Covid-19, o ensino nos níveis de educação básica e superior teve que se readequar à nova realidade e a melhor opção encontrada foi o ensino remoto, que devido à inesperada mudança, também é chamado de ERE. Toda a educação teve que se organizar e reorientar as diretrizes voltadas para qualificar, repentinamente, o corpo docente; viabilizar o acesso dos alunos a recursos tecnológico com suporte de internet; distribuir atividades impressas para alunos sem recurso tecnológico; dar suporte psicológico aos alunos em virtude da sobre carga emocional exigida pelo distanciamento social; priorizar os alunos com alguma deficiência ou necessidade educacional específica, enfim, a escola se voltou cada vez mais para além dos quatro muros que delimitam um espaço físico (Saidia et al, 2021).

Nesse contexto educacional, as tecnologias da informação e comunicação (TIC), mais do que nunca, desempenham um papel principal no processo de ensino e aprendizagem. Para Leite (2014, p. 56) "as TIC agrupam ferramentas informáticas e telecomunicativas como: televisão, vídeo, rádio, Internet etc.[...] Agora, além da escola, também a residência, a empresa e os ambientes sociais podem se tornar espaços educativos". Fernandes, Rodrigues e Ferreira (2020) esclarecem que o ensino, tendo o aluno como protagonista, mediado pelas TIC deve pautar-se nos domínios social, afetivos e cognitivos, sendo o último desenvolvido pela argumentação científica.

Dentre os ambientes virtuais mais utilizados pelos professores, o Google Sala de Aula (GSA) ou Google Classroom é o que tem apresentado maior destaque devido à organização e adaptação mais fácil com o ambiente da sala de aula, e por isso 
tem sido utilizando como tema em diversos artigos científicos (Duque Pereira et al, 2018; Lima \& Netto, 2018; Costa, et al, 2019). Ressalta-se que o GSA não é uma ferramenta nova, entretanto poucos professores utilizavam no ensino presencial o híbrido. Essa ferramenta é de acesso livre e faz parte do pacote oferecido pela plataforma Google sendo necessária um registro de conta. Com ele, o professor pode organizar turmas separadamente; crias disciplinas e por módulos ou unidades; postar atividades assíncronas e notas dos alunos; gerar link automaticamente para os momentos síncronos, entre outras funcionalidades.

Nas aulas remotas é necessário que os professores utilizem ferramentas indispensáveis para estimular os alunos e tornar mais dinâmico o processo de ensino, uma vez que o distanciamento impõe barreiras espaciais que implicam em desinteresse, ansiedade e frustação (Schimiguel, Fernandes \& Okano, 2020). No Quadro 1 abaixo é feito um levantamento de algumas ferramentas que podem auxiliar o professor nos momentos síncrono e assíncronos.

Quadro 1. Principais ferramentas utilizadas no ensino remoto.

\begin{tabular}{|c|c|c|c|}
\hline Ferramenta & Proposta de ensino & Tipo de atividade & Referência \\
\hline Google Classroom & $\begin{array}{l}\text { Sala de aula virtual e } \\
\text { interativa }\end{array}$ & $\begin{array}{l}\text { Assíncronas e síncronas } \\
\text { através de extensões dos } \\
\text { pacotes da Google }\end{array}$ & $\begin{array}{l}\text { Swaminathan et al, } \\
2020 .\end{array}$ \\
\hline Google meet & $\begin{array}{l}\text { Software utilizado para } \\
\text { os momentos síncronos }\end{array}$ & $\begin{array}{l}\text { Interação online } \\
\text { professor/alunos e } \\
\text { aluno/aluno }\end{array}$ & $\begin{array}{l}\text { Roig-Vila et al, } \\
2021 .\end{array}$ \\
\hline Moodle & $\begin{array}{l}\text { Software utilizado para } \\
\text { apoio às atividades de } \\
\text { ensino }\end{array}$ & $\begin{array}{l}\text { Momentos assíncronas e } \\
\text { síncronas; atividades } \\
\text { colaborativas }\end{array}$ & $\begin{array}{l}\text { Durão e Raposo, } \\
2020 .\end{array}$ \\
\hline Kahoot & Software Gamer & $\begin{array}{l}\text { Aplicação de conceitos; } \\
\text { avaliação }\end{array}$ & $\begin{array}{l}\text { Wang el Tahir, } \\
2020 .\end{array}$ \\
\hline Simulador PhET & $\begin{array}{l}\text { Laboratório virtual; } \\
\text { ensino ativo }\end{array}$ & $\begin{array}{l}\text { Aplicação de conceitos, } \\
\text { leis e teorias; }\end{array}$ & Passos et al, 2019. \\
\hline Jamboard & Lousa/quadro interativo & Trabalhos em grupo; & Saidia et al, 2021. \\
\hline Padlet & $\begin{array}{l}\text { Murais; cronogramas e } \\
\text { organogramas }\end{array}$ & $\begin{array}{l}\text { Trilhas de } \\
\text { aprendizagem; inserção } \\
\text { de imagens, áudios e } \\
\text { vídeos }\end{array}$ & $\begin{array}{l}\text { Alrasheedi e } \\
\text { Capretz, } 2015 .\end{array}$ \\
\hline
\end{tabular}

Edpuzzle $\quad$ Ensino interativo $\quad$ Produção de vídeos $\quad$ Tabassum, 2020.

\begin{tabular}{llll} 
Entrevistas sobre & Criar áudios com os & Ifedayo, Ziden e \\
assuntos diversos & $\begin{array}{l}\text { conteúdos das diversas } \\
\text { disciplinas }\end{array}$ & Ismail, 2021. \\
\hline
\end{tabular}

Fonte: Autores (2021).

Ressaltamos que todas os instrumentos supracitados não são criações novas, mas vêm tendo destaque junto às tecnologias da informação e comunicação no trabalho docente impactando positivamente o processo de ensino e aprendizagem ao aproximar os alunos de ferramentas tecnológicas que motivam e dão dinamismos aos conteúdos; às aulas síncronas; os processos avaliativos; desenvolvem trabalhos colaborativos; além de abrir espaço de discussão nos cursos de formação docentes na perspectiva de preparar os futuros professores para novos desafios. 


\section{Metodologia}

A pesquisa em questão tem natureza qualitativa evidenciando a qualidade social, e do tipo descritiva, que no âmbito educacional, privilegia o processo em detrimento de um produto final. Não tem como objetivo simplesmente comprovar ou refutar hipóteses, mas sim compreender a reconstrução dos conhecimentos produzidos durante a investigação; valorizar o desenvolvimento dos sujeitos da pesquisa e mostrar a essencialidade de se considerar a subjetividade de todos os envolvidos no contexto em questão, que são o pesquisador e os sujeitos pesquisados (Lüdke \& André, 1986; Gil, 2009, 2010; Moraes \& Galiazzi, 2011). Para a explorar as concepções dos sujeitos pesquisados acerca do ensino remoto emergencial (ERE) foi atualizado a análise textual do discurso, conforme proposto do Moraes e Galiazzi (2011).

ERE foi analisado durante a disciplina de Química Geral I, em uma turma do $1^{\circ}$ período do curso de licenciatura em Química do Instituto Federal do Rio Grande do Norte localizado no interior do estado potiguar. Dos 28 estudantes matriculados na turma virtual do Google Classroom, 17 estudantes se dispuseram em contribuir com a pesquisa, sendo 5 do sexo feminino e 12 do masculino. Conforme documento que regulamentou o ERE, resolução no 22/2020- CONSUP/IFRN, as disciplinas na licenciatura foram ministradas em módulo de 5 semanas sendo a carga horária dividida em $30 \%$ de momentos síncronos e 70\% de momentos assíncronos. Levando em consideração essa proporção, para cada 2 aulas ministradas durante os momentos síncronos havia 4 aulas de momentos assíncronos. A disciplina supracitada teve início de forma presencial com desenvolvimento de $26 \%$ da carga-horária, sendo retomada em outubro de 2020 no formato remoto.

A plataforma utilizada para as aulas online (momentos síncronos) foi o Google meet utilizando sempre o mesmo link de acesso visível no mural do Google Classroom. No total foram realizados 11 encontros síncronos para ministração dos conteúdos da ementa da disciplina e propostas de atividades com uso de recursos tecnológicos. Para os momentos assíncronos foram disponibilizados materiais, tais como slides, artigos científicos e vídeo aulas gravadas. Como instrumentos avaliativos, foram utilizados pelo professor, a participação dos alunos durante as aulas, formulários com questões objetivas, listas de exercícios com questões discursivas e apresentação de seminários.

Todas as aulas foram gravadas com consentimento dos alunos e posteriormente disponibilizadas numa pasta para acesso dos alunos às gravações. Foi alertado que era terminantemente proibida a divulgação parcial ou total das gravações com o objetivo de evitar exposição (professor e alunos) e, eventualmente bullying ou constrangimentos desnecessários.

No final da disciplina, foi aplicado um questionário com questões fechadas (poderia ter mais de uma alternativa correta) e uma questão (discursiva) através do google formulário para obter uma perspectiva na visão dos alunos sobre os desafios do ensino nesse novo formato imposto pela pandemia. A análise desse questionário serviu de base para construção de potenciais significados dos resultados do ERE, propor mudanças nas estratégias de ensino, ter um olhar crítico e reflexivo das práticas pedagógicas, rever metodologias e dá voz aos protagonistas do processo de ensino, que são os alunos.

\section{Resultados e Discussão}

Conforme pode se observar no gráfico 01, para os alunos, as maiores dificuldades encontradas no ensino da disciplina de Química Geral I estão relacionados à falta de um ambiente adequado para a realização dos estudos durante as atividades assíncronas. Cerca de $42 \%$ relataram isso em decorrência de vários fatores que podemos relacionar, como por exemplo, conflitos familiares, espaço pequeno e compartilhado com os demais familiares, dificuldade em concentração para estudar devido barulhos entre outros. Ressaltamos que as porcentagens mostradas nos gráficos que seguem, podem apresentar um universo de mais de 100\%, uma vez que representam as concepções dos alunos sobre o ERE investigadas através de questionários abertos que possibilitam os alunos marcarem mais de uma opção que defina seu pensamento a respeito dos questionamentos. 
Gráfico 1. Dificuldades dos alunos no processo de ensino e aprendizagem no contexto do ERE.

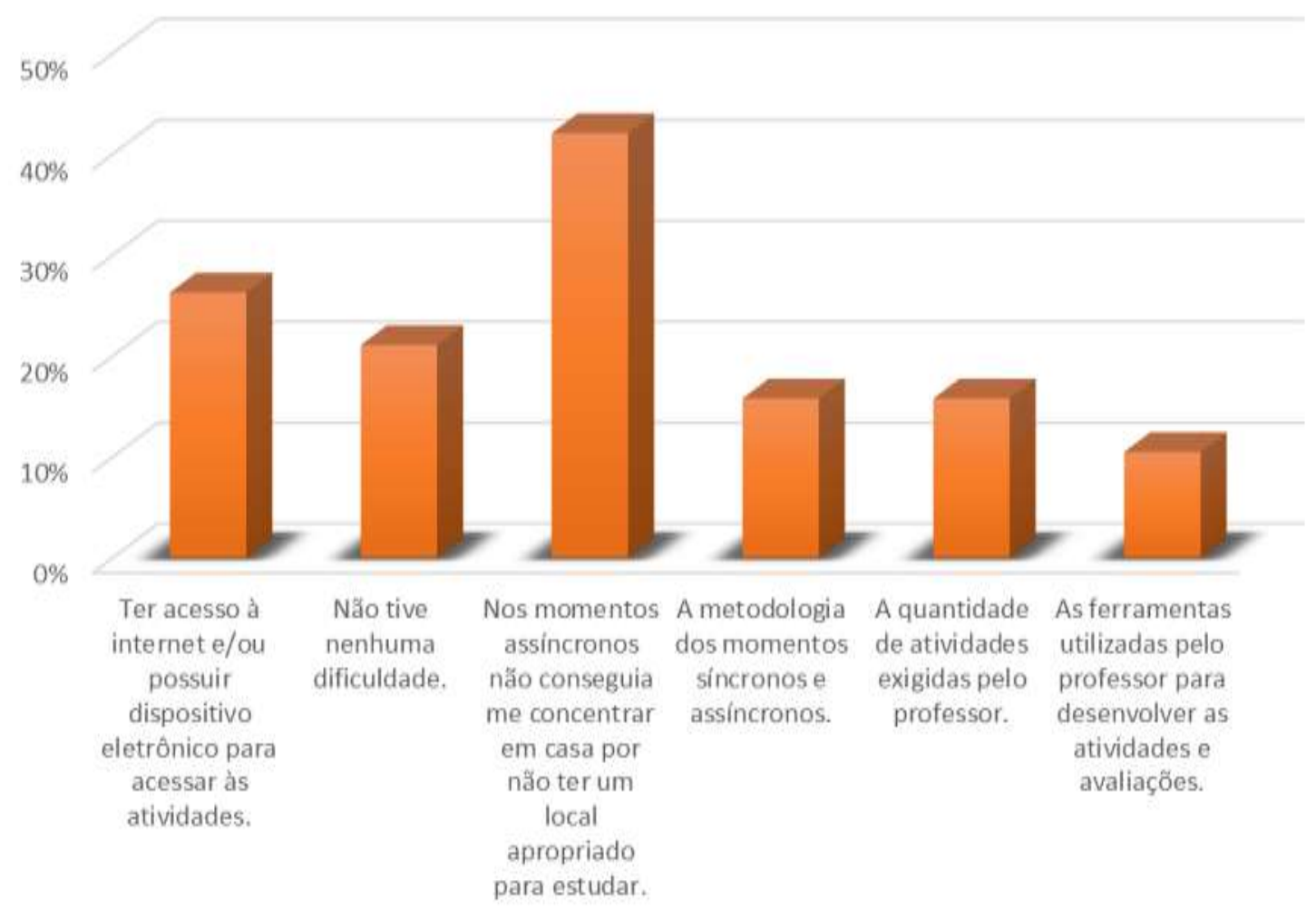

Fonte: Autores (2021).

Ainda referente ao Gráfico 1, podemos inferir que a queixa de quase $30 \%$ dos alunos diz respeito ao acesso precário à internet ou a dispositivos eletrônicos para assistirem às aulas e acompanhar as atividades. É realidade comum das populações do interior a baixa qualidade de acesso à internet e, mais ainda, quando analisamos a realidade de alunos que moram na zona rural. Alguns têm acesso à internet apenas através de dados móveis e recorrentemente saem dos encontros síncronos devido a oscilações na rede de internet.

Outro determinante no ERE é o fato dos módulos condensarem os momentos síncronos levando em consideração a distribuição da carga horário e a proporção de 1:3 (momentos síncronos: momentos assíncronos). Entretanto, como pode ser observado pelo Gráfico 2, cerca de $68 \%$ dos alunos consideraram a quantidade de momentos síncronos suficientes para tirar dúvidas e discutir a respeito dos conteúdos ministrados. 
Gráfico 2. Suficiência dos momentos síncronos para os alunos tirarem suas dúvidas.

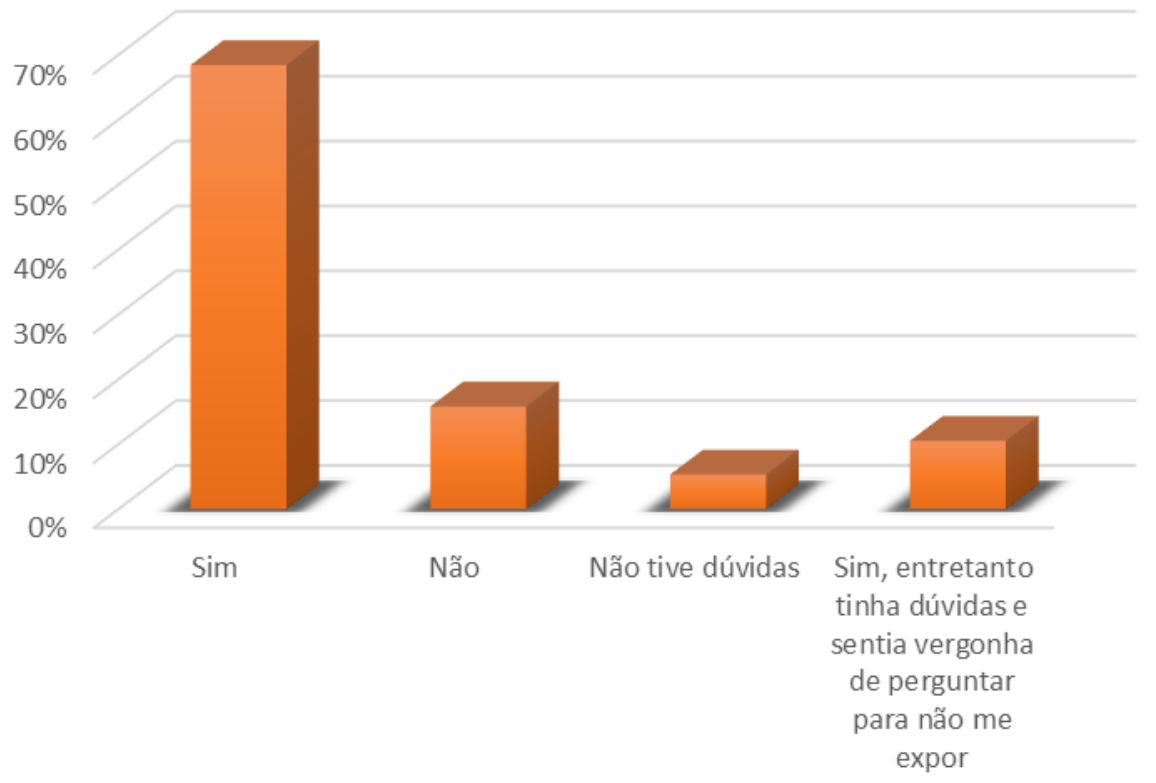

Fonte: Autores (2021).

Ainda analisando o Gráfico 2, para 15,8\% dos alunos os momentos síncronos foram insuficientes para tirar as dúvidas e 10,5\% consediraram suficientes, entretanto sentiam vergonha de pergutar sobre sua dúvida por medo de se expor em frente aos demais colegas. Salientamos que a decisão em voltar às atividade de ensino remotamente através de módulos passou por consulta à toda comunidade acadêmica e as discussões perpassaram as diversas instâncias do IFRN, sendo na visão dos professores, alunos e diretores dos campi, o melhor formato para o retorno. Não obstante, é concebível a ideia de que seria muito cansativo e prejudicial ao ensino obrigar os estudantes assistirem as aulas durante um turno inteiro, seja manhã ou tarde, como na presencialidade, uma vez que a realidade é diferente e nos impõe uma dinâmica nova.

Para Amaral e Polydoro (2020), um dos desafios encontrados pelos estudantes no ERE é desenvolver durante os momentos assíncronos uma rotina de estudos e procurar construir o conhecimento de forma autônoma através dos recursos disponibilizados pelo professor, tais como artigos, slides produzidos, ativiades propostas, pesquisas na internet, entre outros. Em pesquisa recente realizada por Nunes (2021) com estudantes de graduação durante o ensino remoto mostrou que os efeitos na vida acadêmica e pessoal têm se detacados, acarretando baixos rendimentos escolares, estresses e ansiedade que podem levar aos estudantes evadirem.

Nesse contexto, conforme demonstrado no Gráfico 3, aproximadamente $63 \%$ dos alunos afirmaram ter dificuldades no desenvolvimento dos estudos sem a presença do professor e que procuraram dirimir essas dificuldades pesquisando em ferramentas disponíveis, como internet, artigos e livros. Contudo, para cerca de 32\% os conteúdos eram vistos como complexos para serem estudados sozinho. Isso pode ser visto como preocupante nesse formato de ensino uma vez que parte dos alunos não conseguem tirar as dúvidas formuladas nos momentos aasíncronos durante os momentos síncronos por motivos apresentados na análise do Gráfico 2. Ainda para 10\% dos entrevistados, a maior dificuldade nos momentos assíncronos foi a grande quantidade de ativiades acumuladas da dsiciplina de Química Geral I com outras disciplinas em que estavam matriculados. 
Gráfico 3. As maiores dificuldades dos alunos nos momentos assíncronos.

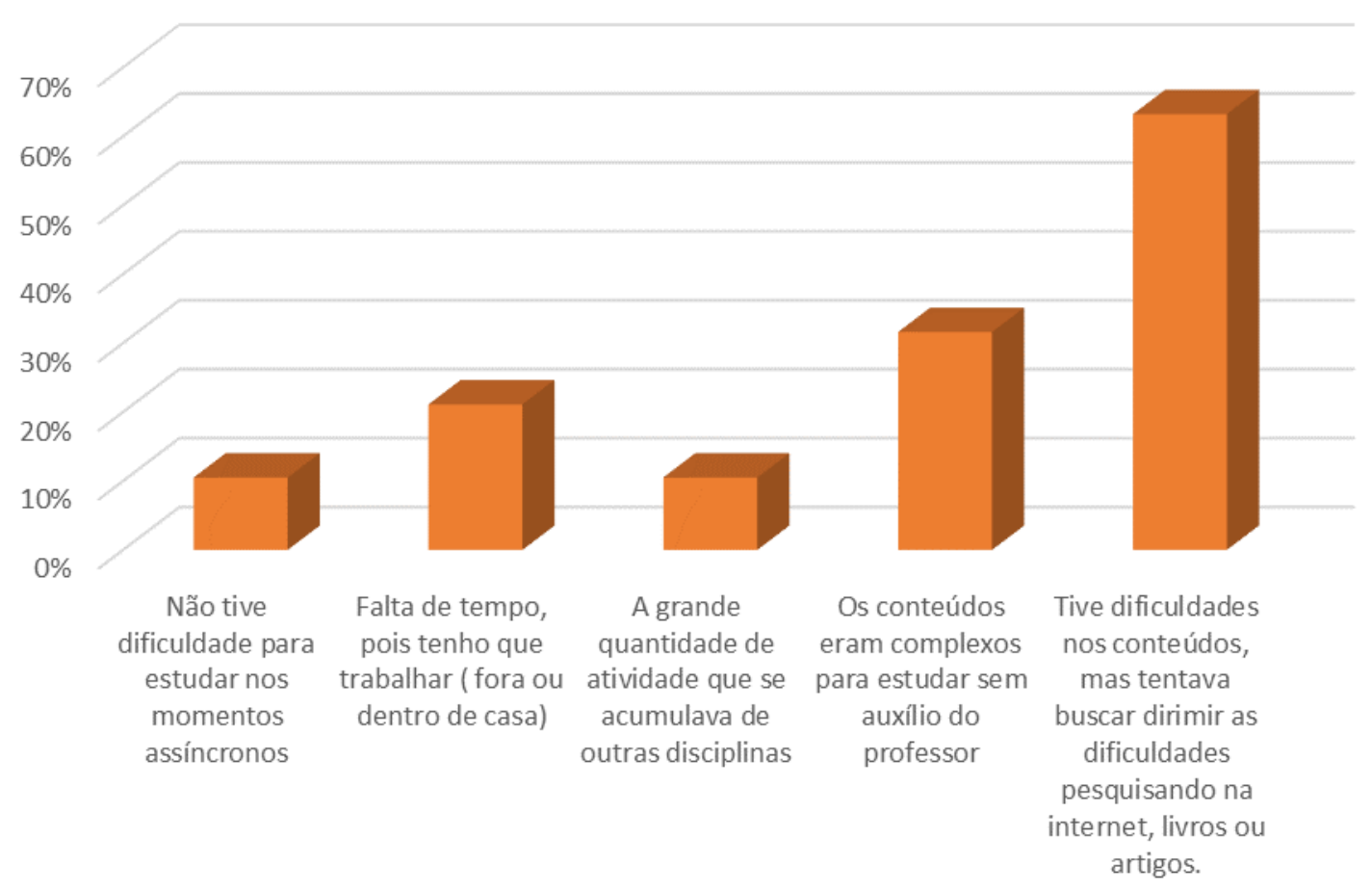

Fonte: Autores (2021).

Considerando o impacto social de uma pademia na vida da população, Garrido e Rodrigues (2020) ressaltam que a saúde metal é a mais afetada em virtude das mudanças repentinas, como isolamento social. Quando confrontamos essa realidade como o ensino, nos deparamos com situações descritas no Gráfico 3, onde mostra que 21,1\% dos alunos sentiram dificuldade em acompanhar as atividades assíncronas porque tinham que trabalhar dentro ou fora de casa. Isso deve-se aos efeitos das restrições de circulação que impedem algumas tividades remuneratórias, como por exemplo, de vendas e obrigam as pessoas trabalharem de casa. Para traçarmos uma linha de comparação entre o ERE e o ensino presencial, os alunos foram questionados quanto à diferença entre os dois modelos de ensino. Para 80\% dos alunos (Gráfico 4), o ambiente da aula no presencial é mais empolgante que no ensino remoto emergencial, e isso é perceptível uma vez que durante os momentos síncronos há pouco feedback como demonstrado também por Amaral e Polydoro (2020). 
Gráfico 4. Diferença entre ERE e o ensino presencial, de acordo com os alunos.

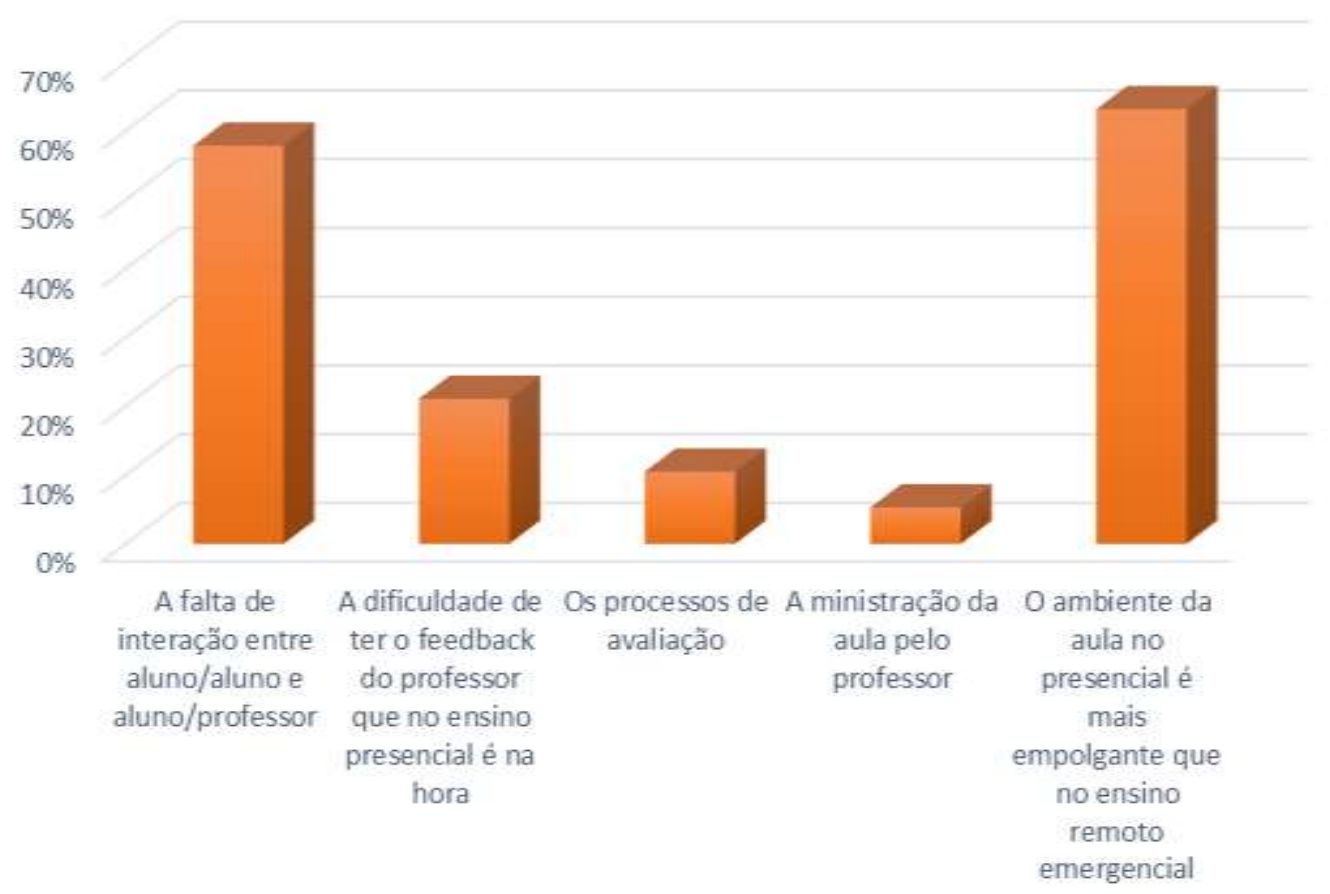

Fonte: Autores (2021).

Sem dúvidas, o ambiente escolar é imbuído de intensas interações entre todos os sujeitos que constituem a escola sejam estes professores, alunos, gestores, apoios pedagógico e técnico-administrativo, seguranças e auxiliares de serviços gerais, jardineiros, comunidade ao entorno, pais e responsáveis, enfim, são as relações entre todos os citados anteriomente que fazem com que o conhecimento seja construído. Nesse contexto, a sala de aula é relatada como o ambiente mais propícios para troca de conhecimentos específicos e de conteúdos entre os alunos através da interação presencial com o professor, além das relações afetivas e cognitivas propiciadas pelo ambiente. (Maldaner \& Santos, 2010; Libâneo, 2011; Carvalho \& Gil-Pérez, 2011; Sasseron, 2015; Fernandes \& Ferreira, 2020). Esse fato é corroborado na mesma fala dos alunos quando cerca $57,9 \%$ relatam que no ERE não é possível a interação entre aluno/aluno e entre aluno/professor tal qual existe no ensino presencial, e isso é refletido na dificuldade de ter o feedback do professor, como é ressaltado por $21 \%$ dos alunos.

Os professores precisam de um olhar mais crítico e reflexivo para avaliar os alunos no contexto do ERE levando em consideração os aspectos qualitativos e formativos em detrimento dos aspectos quantitativos, uma vez que as avaliações tradicionais não têm mais espaço nesse contexto formativo (Dantas, Massoni \& Santos, 2017). Assim, os alunos foram avaliados com o objetivo de despertar neles próprios um olhar mais reflexivo sobre o papel das avalições usando as novas tecnologias. Entretanto, sabemos que a química possui uma linguagem científica própria através de simbologias, deduções de equações, reações químicas entre outras, de forma que é importante o professor ter essa percepção dos seus alunos. Assim, os alunos foram avaliados através de atividades com Google forms, participação nas atividades com recursos tecnológicos durante os momentos síncronos (como exemplo, a atividade desenvolvida com uso de um simulador), seminários em grupos e, por último, por listas de exercícios em que o professor pôde ver a organização e a aplicação do uso adequado da linguem própria da química. Com relação ao processo de avaliação, $84,2 \%$ dos alunos ficaram satisfeitos com a nota atribuída ao seu desempenho e com as estratégias avaliativas adotadas pelo professor. Ressaltamos que os critérios de notas servem prioritariamente para alimentar um sistema numérico para critérios de aprovação e reprovação, de maneira tal que, um aluno 
com média baixa ou insuficiente, não significa que não pode ser um excelente profissional e cidadão crítico-reflexivo no mundo contemporâneo e tecnológico.

Como futuros professores, os alunos foram indagados quanto à expectiva sobre sua formação e preparação para possivelmente atuarem no ensino durante uma pandemia que obrigasse as escolas adotarem o formato de ensino remoto. Para 73\% dos alunos os cursos de licenciatura precisam trabalhar mais as tecnologias voltadas para o ensino em formatos diferentes do presencial. A experiência vivenciada pelos alunos é, de certa forma, uma imersão no uso de tecnologias voltadas para o ensino sendo possível vislumbrar a formação acadêmica destes aliada à formação tecnológica. Contudo salientamos a importância de disciplinas mais específicas que trabalhe com as tecnologias de informação e comunicação os aspectos pedagógicos, estruturais e seus impactos à educação (Leite, 2014; Fernandes, Rodrigues e Ferreira, 2020).

Como destacado por vários estudiosos da área de ensino e formação docente (Maldaner \& Santos, 2010; Libâneo, 2011; Carvalho \& Gil-pérez, 2011; Chassot, 2015; Zompero \& Laburu, 2011; Trópia, 2011; Sasseron, 2015; Belluco \& Carvalho, 2014) é fundamental, o próprio sujeito em formação, tomar consciência que as implicações das demandas educacionais surgem como reflexo das vivências durante os cursos de formação inicial ou continuada dos professores. Nesse pensamento, os sujeitos foram questionados sobre suas perspectivas docentes como futuro professor de químicas quanto a uma possível pandemia que obrigasse as escolas continuarem com o ensino no formato remoto (Gráfico 5).

Gráfico 5. Perspectiva para formação docente quanto ao ensino remoto.

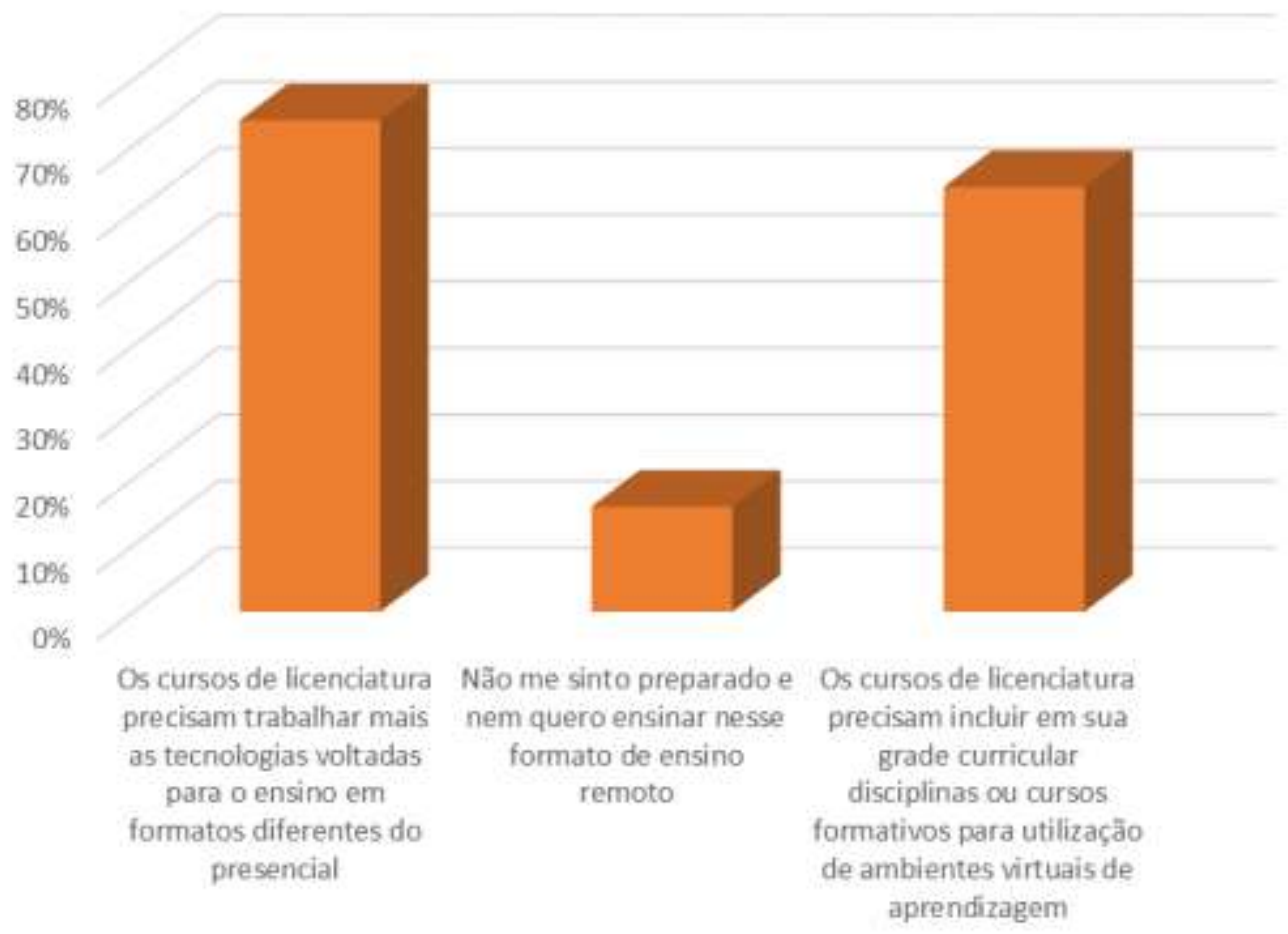

Fonte: Autores (2021).

Conforme pode ser visto, a grande maioria dos alunos descreveram que possuem perspectivas de que durante sua formação possam ser preparados para usar as ferramentas adequadas para o formato do ensino remoto. Isso evidencia que os cursos de formação docente precisam debruçar-se cada vez mais no uso de ferramentas tecnológicas bem como as implicações destas para o ensino. Repensar nesse formato de ensino requer o contato mais intenso e recorrente entre os futuros professores e ERE, e nesse contexto, podemos citar como momentos formativos exitosos, cursos de extensão, projetos de pesquisas e até 
mesmo trabalhos de conclusão de curso para colocar em prática os conhecimentos construídos a respeito das ferramentas tecnológicas voltadas ao ensino no novo formato.

Uma grande preocupação do IFRN foi fornecer a todos os alunos o acesso ao ensino de qualidade, e para tanto, criou junto à assistência estudantil um auxílio para os alunos com dificuldade de acesso à internet e a aparelhos eletrônicos. De certo modo, esse contato direto pode se refletir como uma formação por imersão ao universo tecnológico e ferramentas de ensino. Do total de alunos entrevistados, 47,4\% não precisaram do auxílio, 42,1\% tiveram a solicitação deferida e apenas $10,5 \%$ tiveram a solicitação indeferida, conforme mostrado no Gráfico 6 a seguir.

Gráfico 6. Auxílio aos estudantes com dificuldade de acesso à internet e a aparelhos eletrônicos.

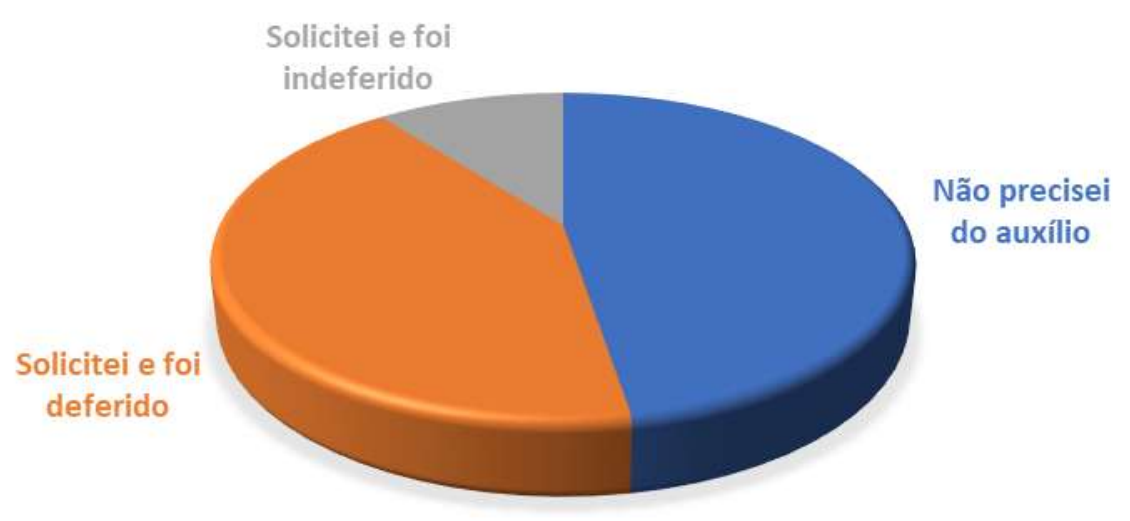

Fonte: Autores (2021).

No Quadro 2 a seguir é mostrado um breve relato das experiências de alguns alunos em relação ao ERE. Percebemos que todos tiveram experiencias exitosas e que isso deverá impactar positivamente na sua formação. Os recortes das falas escritas foram extraídos na íntegra e seguem certas categorias experienciais conforme tentamos mostrar. 
Quadro 2. Relatos de experiência dos alunos na disciplina de Química Geral I durante ERE.

"Apesar de ser a minha primeira experiência de ensino remoto pra mim foi bastante produtivo consegui absorver bastante os conteúdos aplicado pelo professor porque não ficava só nas aulas remotas tentava explorar os conteúdos apresentados com aulas complementares pelo YouTube." (Aluno A)

"Foi bem tranquilo. Por mais que estivéssemos em adaptação, não houve tantos problemas." (Aluno B)

“Gostei, o professor fez o que pode para nos ensinar, e eu conseguir entender.” (Aluno C)

"Bom foi uma experiencia tanto inédita para mim, mas essa experiencia servil para me habituar um pouco mais sobre o ensino remoto." (Aluno D)

"Foi uma experiência boa e desafiadora, no qual houve muito esforço para conseguir cumprir os objetivos, mas no final deu certo." (Aluno E)

"Foi uma experiência gratificante, aprendi muito apesar de algumas dificuldades, mas de certo modo super valeu a pena!" (Aluno F)

"Minha opinião sobre a disciplina é que no meu ver foi um pouco complicado em relação há formulários (atividades avaliativas) no começo devido a nunca ter utilizado essa ferramenta, mas no mais eu achei bem proveitoso." (Aluno G)

"Não fiquei tão satisfeita com as notas, devido falta de esforço meu, para mim é desinteressante e cansativo ficar com a cara em um computador e isso desinteressa o aluno." (Aluno H)

"Primeiramente é desinteressante e cansativo ficar com a cara no computador, eu não estou satisfeita com minhas notas, porém isso é consequência da minha falta de interesse devido o modo EAD das aulas." (Aluno I)

"A principio encontrei dificuldades para entender os conteúdos, mais as aulas síncronas onde o professor respondeu algumas dúvidas específicas, me ajudou e melhorou o compreender dos assuntos. Em relação ao professor, gostei da metodologia, e principalmente da acessibilidade em tirar dúvidas dos discentes." (Aluno J)

"Pra mim foi relevante, mas no início sentir dificuldades, mas com o passar dos dias fui me adaptando." (Aluno L)

"A princípio encontrei dificuldades para entender os conteúdos, mais as aulas síncronas onde o professor respondeu algumas dúvidas específicas, me ajudou e melhorou o compreender dos assuntos. Em relação ao professor, gostei da metodologia, e principalmente da acessibilidade em tirar dúvidas dos discentes." (Aluno M)

"Devido ao pouco tempo que tínhamos estudado e a volta das aulas sendo remota e com menos tempo dificultou, mas principalmente por não termos o professor presencial para tirar as dúvidas principalmente nos exercícios." (Aluno N)

"No início do Módulo, tive um pouco de dificuldade devido o processo de adaptação ao professor e até mesmo a volta às aulas, uma vez que estávamos parados a cerca de 8 meses inteiros. Mas com o tempo, acabei me acostumando e ficou mais fácil de resolver questões e até mesmo compreender o assunto das aulas com maior facilidade." (Aluno $\mathrm{O}$ )

Relatos negativos: dificuldade de construir conhecimento devido ao novo formato de ensino.
Relatos positivos: construção de conhecimento através da superação de alguns obstáculos impostos pelo período que vivemos.

\section{Relatos} negativos/positivos: dificuldade inicial na construção de conhecimento, mas superada no decorrer de algum tempo.

"A principio tive bastante dificuldade para ter acesso remoto, mas com ajuda do auxílio facilitou meu acesso. Logo em seguintes veio a troca de professores, e com isso foi feito uma nova adaptação comigo e com a turma. Mas o professor atendeu bem nossos pedidos, com cuidado de tirar dúvidas, nivelar a turma, sendo bastante flexível, disponibilizou bastante conteúdo, fez gravação de aulas...” (Aluno P)

"Confesso não ter tido um rendimento nem próximo do desejado, mas estou satisfeito dadas as circunstâncias que enfrentei, como: tempo sem estudar até recomeçar de forma bem corrida, falta de tempo em dias aos quais tive que sair para trabalhar, problemas com conciliação familiar para ter um ambiente mais propício a estudar." (Aluno Q) 
Como pode ser observado no Quadro 2, foram criadas três categorias para melhorar a interpretação dos resultados das falas escritas dos alunos. A primeira é nos dá uma visão positiva do processo de ensino e aprendizagem durante o ERE na medida que os alunos $A, B, C, D, E$ e $F$ se mostraram desafiados desde o início adquirirem uma postura mais autônoma e construir o conhecimento através da superação de alguns obstáculos impostos pelo período que vivemos, como citado pelo aluno que se viu à vontade para "explorar os conteúdos apresentados com aulas complementares pelo YouTube" e, assim, não deter-se apenas aos momentos síncronos para assimilação dos conteúdos.

$\mathrm{Na}$ segunda categoria chamamos de relatos negativos, apesar de não necessariamente ser de fato negativo, mas nos chamou atenção porque para esses alunos o rendimento no ERE não foi favorável e não correspondeu às expectativas. Para os alunos $G, H$ e $I$ o ERE evidenciou-se como complicado, cansativo e desinteressante devido ao formato que parece de certo modo com ensino à distância onde a ferramenta mais utilizada é o computador, sendo as atividades avaliativas através dos formulários complicadas. Ressaltamos que o formato de ensino remoto apenas se asseme lha a EAD em alguns recursos midiáticos, sendo a interação entre professor/aluno e entre aluno/aluno mais intensa no ERE proporcionada pelos momentos síncronos e o constante diálogo do professor com a turma, como é o caso dos grupos de Whatzapp criados, além de outros recursos como o Google Classroom e ainda e-mail.

Por último, percebemos que a terceira categoria representa àqueles alunos que tiveram uma visão positiva do ERE depois certo tempo de experiência, ou seja, inicialmente encontraram alguns obstáculos, mas conseguiram superá-los após determinado período. Assim, para os alunos $J, L, M, N, O, P$ e $Q$ algumas dificuldades como adaptação ao ensino nesse novo formato, se dividir entre as aulas e o trabalho, ter passado muito tempo sem estudar. Entretanto, esses todos esses alunos relataram que foi possível buscar um melhor rendimento e superar suas dificuldades e limitações.

\section{Considerações Finais}

Os desafios impostos por um inimigo invisível (vírus SARS-cov-2) mostrou o quão frágil são os sistemas e recursos viabilizados pelo ser humano, forçando o fechamento de comércios, indústrias, órgãos públicos e os espaços físicos de aprendizagem, tais como escolas, universidade e museus. Nesse contexto, os professores foram os mais impactados em rever as suas abordagens de ensino, onde a maioria não tinha formação prática para lidar tão de perto e repentinamente com o uso das tecnologias da informação e comunicação (TIC). Reflexos direto no conhecimento de conteúdos essenciais para formação dos alunos, crises de ansiedade devida ao distanciamento social, falta de recursos para ter qualidade nas aulas online (momentos síncronos e assíncronos) e perspectivas para retorno à presencialidade são fatores, que por muito tempo, permearam as preocupações de professores, gestores e alunos.

No cenário dos cursos de formação docente, podemos acentuar que os professores em formação foram convidados por imersão às TIC e a refletir sobre o papel delas na construção do conhecimento numa sociedade cada vez mais digital e tecnológica onde a comunicação se dá tão rápida quanto um clique em um smartphone. Além disso, é esperado desses futuros professores uma autoavaliação no sentido de refletirem criticamente a respeito de sua própria formação com viés a proporcionar qualidade de ensino e modificar a realidade das aulas quando estiverem lecionando.

Quanto às abordagens desenvolvidas e ferramentas de ensino, foi possível mostrar que no formato do ensino remoto privilegia-se a educação emancipadora com propostas que favorecem uma visão de protagonista dos alunos, uma vez que eles próprios detêm em suas casas instrumentos para aquisição novos conhecimentos ou aprofundamentos proporcionados pelos recursos digitais. Tal concepção de ensino e aprendizagem, nesse contexto, inclui o ensino com os princípios da investigação que busca colocar o sujeito como ativo na construção do próprio conhecimento e nos leva a refletir sobre as possibilidades do ensino que se distancia do tradicional à medida que podemos incluir em nossa prática pedagógica marcadores de ensino e avaliações condizentes para exprimir o papel da escola na formação de cidadãos crítico-reflexivos. 
Finalmente foi possível analisarmos sobre as ferramentas mais utilizados pelos professores nos ambientes virtuais de aprendizagem e trazer à discussão a aplicabilidade de cada um nos momentos síncronos e assíncronos durante o ERE, bem como descrevê-las como produção dos conhecimentos advindos das TIC. Apesar das limitações, os alunos pesquisados revelaram experiências mais exitosas e superaram as expectativas quanto ao novo formato de ensino e demonstraram boa aceitação, o que nos leva a refletirmos sobre a perspectiva de desenvolvermos atividades de ensino no ambiente virtual de aprendizagem mesmo durante o ensino presencial, no formato que denominados de ensino híbrido, que integra parte das atividades desenvolvidas ao formato remoto. Essa experiência mostra que um laboratório para estudar e aplicar ferramentas digitais aliadas ao ensino numa abordagem investigativa é viável e abre leques de novas possibilidades com vistas a melhorar a formação docente e, por consequência, o ensino a médio prazo.

\section{Referências}

Alrasheedi, M. \& Capretz, L. F. (2015). An empirical study of critical success factors of mobile learning platform from the perspective of instructors. Procedia - Social and Behavioral Sciences, 176, $211-219$.

Amaral, E. M. \& Polydoro, S. A. (2020). Os desafios da mudança para o ensino remoto emergencial na graduação na Unicamp. Linha Mestra, 41, 52-62.

Andrade, J. P. E. \& Sartori, J. (2018). O professor autor e experiências significativas na educação do século XXI: estratégias ativas baseadas na metodologia de contextualização da aprendizagem. In: Lilian Bacich, L. \& Moran, J. (Orgs) Metodologias ativas para uma educação inovadora: uma abordagem téoricoprática. Penso.

Bachelard, G. (1996). A formação do espírito científico: contribuição para uma psicanálise do conhecimento. Contraponto.

Banerjee, R., Perera, L. \& Tillekeratne, L. M. V. (2021). Potential SARS-CoV-2 main protease inhibitors. Drug Discovery Today, 26, (03), 804-816.

Bellucco, A. \& Carvalho, A. M. P. (2014). Uma proposta de sequência de ensino investigativa sobre quantidade de movimento, sua conservação e as leis de Newton. Caderno Brasileiro de Ensino de Física, 31, (01), 30-59.

Brasil. (2008). Congresso Nacional. Lei $n^{\circ} 11.892$, de 29 de dezembro de 2008. Institui a Rede Federal de Educação Profissional Científica e Tecnológica e dá outras providências. Poder Executivo, Brasília, DF.

Brasil. (2012). Lei $n^{o} 12.677$, de 25 de junho de 2012. Dispõe sobre a criação de cargos efetivos, cargos de direção e funções gratificadas no âmbito do Ministério da Educação, destinados às instituições federais de ensino, altera as Leis nos 8.168, de 16 de janeiro de 1991 , 11.892 , de 29 de dezembro de 2008 , e 11.526, de 4 de outubro de 2007. Poder Executivo, Brasília, DF.

Brasil. (2020). Resolução 22/2020 - CONSUP/IFRN. Regulamenta as medidas de prevenção e enfrentamento à situação de pandemia decorrente do novo Coronavírus (SARS-CoV-2) adotadas no âmbito do Instituto Federal de Educação, Ciência e Tecnologia do Rio Grande do Norte.

Cardoso, S. P. \& Castro, D. L. (2020). O Ensino de química na Rede federal de educação profissional, científica e tecnológica: um espaço rico em possibilidades. Ed. IFPB.

Carvalho, A. M. P. de, \& Gil-Pérez, D. (2011). Formação de professores de ciências: tendências e inovações. Cortez.

Chassot, A. I. (2015). A Ciência é masculina? É, sim senhora! UNISINOS.

Costa, I. M., Mandú, F. N. G., Costa, C. C., Ribeiro, A. F. \& Couto, D. C.C. (2019). Google Sala de Aula como interface de Aprendizagem Baseada em Problema (ABP) No Ensino Superior. In: Anais do XXV Workshop de Informática na Escola. VIII Congresso Brasileiro de Informática na Educação (CBIE). DOI: 10.5753/cbie.wie.2019.792. Acesso em: 27-03-2021.

Duque Pereira, I., Teixeira, M., Alvarenga, M. M. S. C. \& Mansur, A. F. U. (2018). Uma proposta metodológica de ensino híbrido envolvendo a plataforma Google Classroom como ambiente virtual de aprendizagem no Ensino Médio. Revista educação pública. 18, 1-9.

Fernandes, G. W. R., Rodrigues, A. M. \& Ferreira, C. A. R. (2020). Atividades investigativas baseadas em TIC: um estudo dos domínios social, afetivo e cognitivo de crianças e jovens a partir dos fundamentos essenciais da argumentação no contexto da educação científica. Investigações em Ensino de Ciências, 25 (02), 369-387.

García, J.E. \& Porlán, R. (2020). Ensino de ciências e prática docente: uma teoria do conhecimento profissional. In: Harres, J. B. S. (org.). Ensino de ciências: Teoria e prática docente, UNIVATES Editora.

Garrido, R.G. \& Rodrigues, R. C. (2020). Restrição de contato social e saúde mental na pandemia: possíveis impactos das condicionantes sociais. Journal of health \& biological sciences, $8,(01), 1-9$.

Gatti, B. A. \& Barretto, E. S. de S. (2009). Professores do Brasil: impasses e desafios. UNESCO.

Gil, A. C. (2009). Métodos e técnicas de pesquisa social. Atlas.

Gil, A. C. (2010). Como elaborar projetos de pesquisa. Atlas. 
Guimarães, G. M. A., Echeverría, A. R. \& Moraes, I. J. (2006). Modelos didáticos no discurso de professores de ciências. Investigações em Ensino de Ciências, 11, (03), 303-322.

Ifedayo, A. E., Ziden, A. A. \& Ismail, A. B. (2021) Podcast acceptance for pedagogy: the levels and significant influences. Heliyon, v. 7.

Leite. B. S. (2014). M-Learning: o uso de dispositivos móveis como ferramenta didática no Ensino de Química. Revista Brasileira de Informática na Educação, 22, (03), 55-68.

Libâneo, J. C. (2011). Adeus professor, adeus professor? novas exigências educacionais e profissão docente. Cortez.

Lima, F. B. G. de. (2013). A formação de professores nos institutos federais: perfil da oferta. Revista EIXO, 2, (01), 83-105.

Lôbo, S. F. (2008). O ensino de Química e a formação do educador químico, sob um olhar bachelardiano. Ciência \& Educação, 14(1), 89-100.

Lüdke, M. \& André, M. E. D. A. (1986). Pesquisa em educação: abordagens qualitativas. EPU.

Maldaner, O. A. \& Santos, L. P. dos. (2010). Ensino de Química em foco. Ed. Unijuí.

Maués, O., Segenreich, S. \& Otranto, C. (2015). As políticas de formação de professores: a expansão comprometida. Revista Educação em Questão, 51, (37), 42-72.

Moraes, R. \& Galiazzi, M. C. (2011). Análise textual discursiva. Ed. Unijuí.

Nunes, R. C. (2021). Um olhar sobre a evasão de estudantes universitários durante os estudos remotos provocados pela pandemia do COVID-19. Research, Society and Development, 10(3), e1410313022.

Oliveira, R. de S., Sales, M. A. \& Silva, A. L. G. da. (2017). Professor por acaso? A docência nos institutos federais. Revista Profissão Docente Uberaba, 17, (37), 5-16.

Passos, I. N. G., Sousa, J. L. dos S., Sousa, S. F. de. \& Leal, R. C. (2019). Utilização do software PhET no ensino de química em uma escola pública de Grajaú, Maranhão. Revista Observatório, 5, (03), 335-365.

Pena, G. A. de C., Nunes, C. M. F., Souza, K. de L. A. \& Perucci, L. S. (2019). Formação de professores: investigando programas de desenvolvimento profissional docente nos institutos federais. Crítica Educativa, 5, (01), 224-235.

Raposo, A. \& Durão, A. (2020). Desafios do ensino remoto de emergência: da prática à teoria. Interacções, 55, (16), 28-40.

Ribeiro, R. P. \& Nuñez, I. B. (2004). Pensando a aprendizagem significativa: dos mapas conceituais às redes conceituais. In: Nuñez, I. B, Ramalho, B. L. (Org.). Fundamentos do ensino-aprendizagem das ciências naturais e da matemática: o novo ensino médio. Sulina.

Roig-Vila, R., Urrea-Solano, M. \& Merma-Molina, G. (2021). La comunicación en el aula universitaria en el contexto del COVID-19 a partir de la videoconferencia con Google Meet. Revista Iberoamericana de Educación a Distancia, 24 (01), 197-220.

Saidia, R Md., Sharipb, A. A., Rahimc, N. Z. A., Zulkifli, Z. A. \& Zain, S. M. Md. (2021). Evaluating students' preferences of open and distance learning (ODL) tools. Procedia Computer Science, 179, 955-961.

Sasseron, L. H. (2015). Alfabetização Científica, Ensino por Investigação e Argumentação: relações entre Ciências da Natureza e escola. Revista Ensaio, v.17, n. especial, 49-67.

Schimiguel, J., Fernandes, M. E. \& Okano, M. T. (2020). Investigando aulas remotas e ao vivo através de ferramentas colaborativas em período de quarentena e Covid-19: relato de experiência. Research, Society and Development, 9, (09).

Silva, G. M. L. da. \& Netto, J. F. de M. (2018). Um Relato de Experiência Usando Google Sala de Aula para Apoio à Aprendizagem de Química. In: Anais do XXIV Workshop de Informática na Escola. VII Congresso Brasileiro de Informática na Educação (CBIE). DOI: 10.5753/cbie.wie.2018.119. Acesso em: 2703-2021.

Swaminathan, N., Govindharaj, P., Jagadeesh, N. S. \& Ravichandran, L. (2020). Evaluating the effectiveness of an online faculty development programme for nurse educators about remote teaching during COVID-19. Journal of Taibah University Medical Sciences, 16, (02), $268-273$.

Tabassum, A. (2020). Experimental Research on Using Flipped Classroom Approach in Writing Classroom Using Edpuzzle. International journal of english: literature, language \& skills, v. 9, 142-156.

Trópia, G. T. B. de. (2011). Percursos históricos de ensinar ciências através de atividades investigativas. Ensaio: Pesquisa em Educação em Ciências, 13, (01), $121-138$.

Turmena, L. \& Azevedo, M. L. N. de. (2017). A expansão da Rede Federal de Educação Profissional, Científica e Tecnológica: os Institutos Federais em questão. Rev. Diálogo Educ., 17, (54), 1067-1084.

Wang, A. I. \& Tahir, R. (2020). The effect of using Kahoot! for learning - A literature review. Computers \& Education, v. 149.

Zompero, A. F. \& Laburu, C. E. (2011). Atividades investigativas no ensino de ciências: aspectos históricos e diferentes abordagens. Ensaio: Pesquisa em Educação em Ciências, 13, (03), 67-80. 